\title{
Similarity between Natural Wind in the Atmosphere and Model Wind in a Wind Tunnel (II)
}

- Modeling Criteria for a Local Wind -

\author{
by \\ S. Nemoto \\ Meteorological Research Institute, Tokyo \\ (Received February 20, 1961)
}

\begin{abstract}
Part II. Similarity between vertical distribution of mean wind velocity near the ground and that above the model rough surface set in a wind tunnel
\end{abstract}

\begin{abstract}
The similarity between the wind profile near the ground (for example, in the present work the wind profile above the urban district in a typhoon) and that above the rough surface set in a wind tunnel under the neutral state is described from another point of view using the same data previously obtained by Y. TAKAHASHI, K. Soma and S. Nemoro (1951), and then the similarity condition of the wind profile near the ground in the case where the effect of thermal stratification has been taken into account is discussed from another point of view.
\end{abstract}

\section{Introduction}

It has already been well known that the vertical distribution of mean wind velocity near the ground may be expressed by the logarithmic profile in a neutral state. This case, also, is only a special case of the general treatment previously described in Part I, so that it may be a sufficient condition that each eddy Reynolds number of both cases is identical with each other. But another treatment is considered to be possible in such case, where the form of wind profile is known. The present paper will treat this problem.

\section{Wind profiles above the rough surface of a flat-plate set in a wind tunnel}

Wind profiles above the flat-plate (covered over uniformly with wood wool with a thickness of about $35 \mathrm{~mm}$ ) horizontally set in the working section of the wind tunnel (throat diameter: $1.5 \mathrm{~m}$, Göttingen type, range of available wind velocity: $0.5 \sim 60 \mathrm{~m} / \mathrm{sec}$.) are as shown in Fig. 1 (after the experiment made by Y. Takahashi, K. Soma and S. Nemoto, 1951). These wind profiles have been measured by a hot wire anemometer at a distance of $30,60,90,120$ and $150 \mathrm{~cm}$ downwind from the leading edge of the flat-plate for each wind velocity of 50,100 , 210 and $400 \mathrm{~cm} / \mathrm{sec}$. Wind profiles at a distance of 90,120 and $150 \mathrm{~cm}$ among the above-mentioned five distances for each wind velocity were plotted again in semi- 


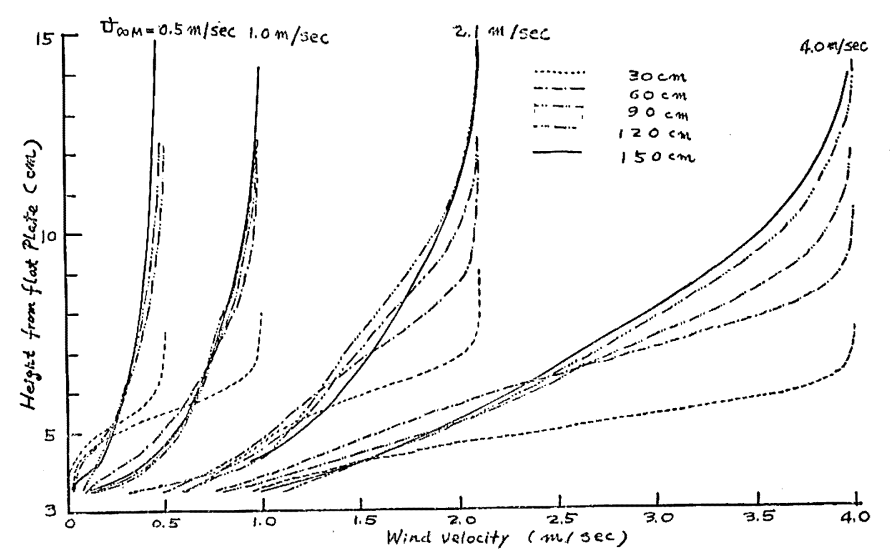

Fig. 1. Wind profiles at each distance downwind from the leading edge of the flat-plate for various wind velocities (after Y. Takahashi, K. Soma and S. Nemoto; 1951).

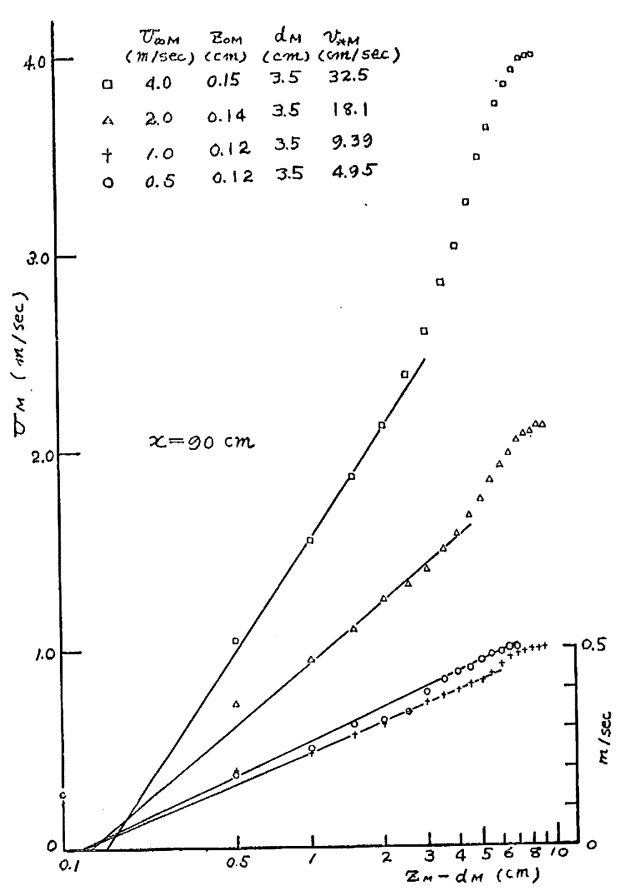

Fig. 2. Wind profiles at $x=90 \mathrm{~cm}$ for various wind velocities (right hand side scale used for only $U_{\infty M}=0.5 \mathrm{~m} / \mathrm{sec}$.).

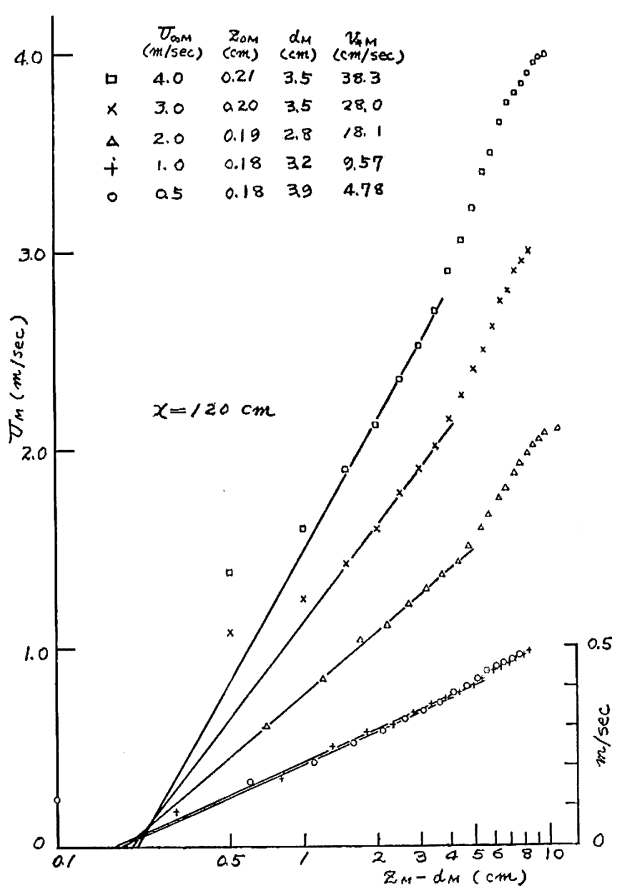

Fig. 3. Wind profiles at $x=120 \mathrm{~cm}$ for various wind velocities.

logarithmic scale section paper, these profiles are shown in Figs. 2,3 and 4 . It will be seen that considering a zero plane displacement, these results can well be represented by the logarithmic profile in the form of 


$$
\frac{U}{v_{*}}=\frac{1}{\kappa} \ln \frac{z-d}{z_{0}}
$$

in the lower layer near the rough surface, where

$U$ : mean wind velocity at a height of $z-d$,

$v_{*}$ : friction velocity

$\kappa$ : KARMAN's constant, 0.4

$z$ : height from the flat-plate,

$z_{0}$ : roughness parameter,

$d:$ zero plane displacement,

and values of $d, v_{*}$ and $z_{0}$ for each case are shown in each figure. And though some of the measured values at the lowest height in these figures are not on curves, this seems to be due to the effect of slight inhomogeneity of states of wood wool covering the flat-plate.

\section{The reduced scale of the height and that of the wind velocity}

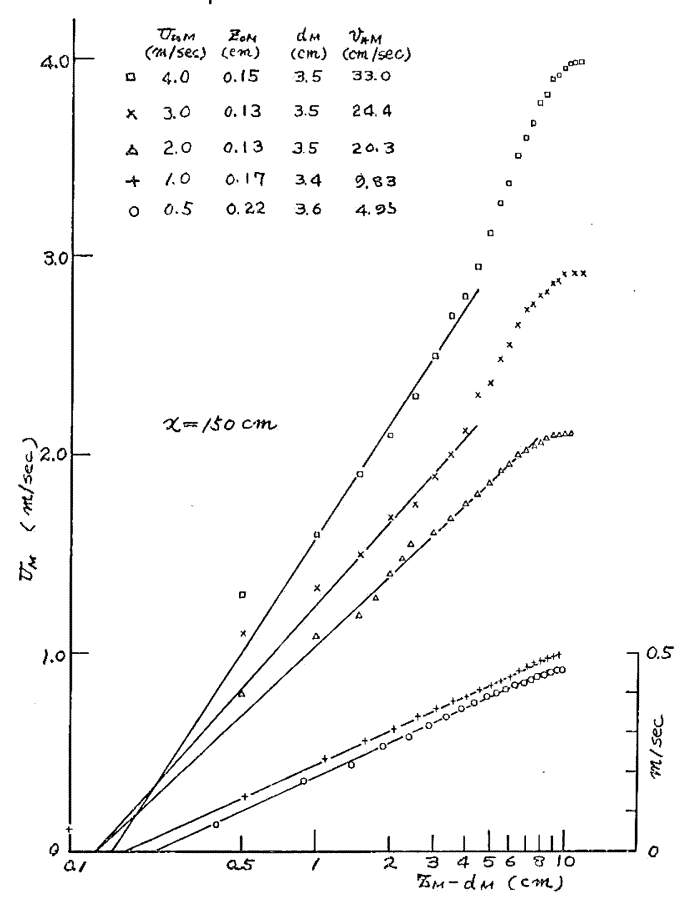

Fig. 4. Wind profiles at $x=150 \mathrm{~cm}$ for various wind velocities.

From the aerodynamical experi-

ment for a large Reynolds number and rough surface, the shearing stress $\tau$ has been found to be proportional to the square of the mean wind velocity. On the other hand, since $\tau=\rho v_{*}{ }^{2}$ (where $\rho$ means air density and $v_{*}$ friction velocity, and $\tau$ is constant and independent of height for a given wind velocity in a neutral surface layer), then

$$
\rho v_{*}^{2} \infty U^{2}(z+d),
$$

where $z$ denotes height from the surface and $d$ denotes zero plane displacement and takes positive, zero, or negative value according to cases. Hence, $v_{*}$ may be expressed as

$$
v_{*}=r(z+d) U(z+d),
$$

where, however, $\gamma(z+d)$ is a non-dimensional parameter used in a similar analysis by A.S. Monin and A. M. OBukhov (1954) and has been represented as

$$
\gamma(z+d)=\frac{\kappa}{\ln \frac{z+d}{z_{0}}},
$$

and has been called friction coefficient, being the objective characteristic quantity expressing the properties of the ground surface to the flow. And from Fig. 5 it will be seen that the relation (3.1) can well be satisfied above the rough surface of the flat-plate set in the wind tunnel. On the other hand, it may be considered that the relation (3.1) will be well satisfied near the ground surface of the atmosphere too. 


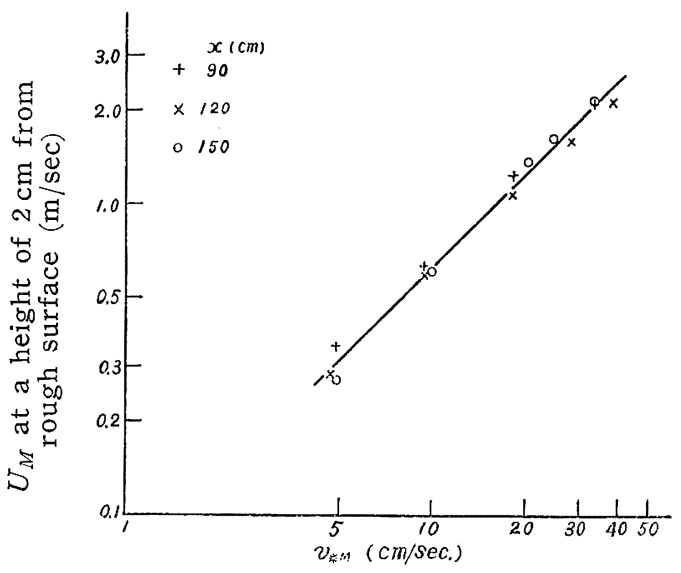

Fig. 5. Relation between mean wind velocity $U_{M}$ and friction velocity $v_{* M}$

Let us now represent friction velocity by

(3.3) $v_{* M}=\gamma_{M}\left(z_{M}+d_{M}\right) U_{M}\left(z_{M}+d_{M}\right)$, for the model flow of the wind tunnel experiment and

$$
\text { (3.4) } v_{* N}=\gamma_{N}\left(z_{N}+d_{N}\right) U_{N}\left(z_{N}+d_{N}\right) \text {, }
$$

for the natural flow in the atmosphere, where the suffixes $M$ and $N$ mean being related to model and prototype, respectively. And if it is supposed that the wind profile above the rough surface of the flat-plate in the model experiment is similar to that of the natural wind near the ground surface, then the dynamical effect of the rough surface to the flow at each corresponding height of both cases need to be equal. In other words, each friction coefficient of each corresponding height of both cases should be equal. That is,

$$
\gamma_{M}\left(z_{M}+d_{M}\right)=\gamma_{N}\left(z_{N}+d_{N}\right),
$$

should be satisfied. From this condition, corresponding height and corresponding wind velocity may be determined. Then, from eqs. (3.2) and (3.5)

$$
\frac{\kappa}{\ln \frac{z_{M}+d_{M}}{z_{0 M}}}=\frac{\kappa}{\ln \frac{z_{N}+d_{N}}{z_{0 N}}},
$$

can be obtained, and from this can be further obtained the following relation:

$$
\frac{z_{M}+d_{M}}{z_{N}+d_{N}}=\frac{z_{0 M}}{z_{0 N}}
$$

That is, in order to satisfy such a condition as (3.5), it will be preferable to choose each corresponding height of both experimental and natural case so that those heights may satisfy eq. (3.7).

On the other hand, for mean wind velocities, from eqs. (3.3), (3.4) and (3.5), similarly,

$$
\frac{v_{* M}}{U_{M}\left(z_{M}+d_{M}\right)}=\frac{v_{* N}}{U_{N}\left(z_{N}+d_{N}\right)},
$$

can be obtained. And this may be also rewritten as

$$
\frac{U_{M}\left(z_{M}+d_{M}\right)}{U_{N}\left(z_{N}+d_{N}\right)}=\frac{v_{* M}}{v_{* N}} .
$$

Therefore, from the above-mentioned description, it may be seen that if the ratio of each corresponding roughness parameter of both cases $z_{0 M} / z_{0 N}$ is chosen as the reduced scale of height then the reduced scale of mean wind velocity is equal to the ratio of each corresponding friction velocity $v_{* M} / v_{* N}$ and the profile 
of the natural wind will become similar to that obtained by the model experiment of the wind tunnel. And so long as wind profiles are expressed by a logarithmic profile, the similarity between the model wind profile in the wind tunnel and the natural wind profile in the atmosphere does apparently hold for any wind velocity.

On the other hand, below approximately 10 to $50 \mathrm{~m}$, it follows directly from the logarithmic wind profile in the adiabatic surface layer that

$$
\varepsilon=\frac{1}{\kappa}\left(\frac{\tau_{0}}{\rho}\right)^{\frac{3}{2}} /\left(z+z_{0}\right),
$$

where $\varepsilon=$ rate of energy dissipation of fluid per unit mass and unit time,

$\tau_{0}=$ surface stress,

and other notations are conventional (LeTTAU, 1961). For given roughness $\left(z_{0}\right)$ and pressure field parameters, such as the geostrophic wind velocity $V_{g, 0}$ at ground level, the $\varepsilon$ values for adiabatic surface layers can be predicted with the aid of the geostrophic drag coefficient $c$ (by using the relation $\left(\tau_{0} / \rho\right)^{\frac{1}{2}}=c V_{g, 0}$; LetTaU, 1959) as follows:

$$
\varepsilon=\frac{c^{3} V^{3}{ }_{g, 0}}{\kappa} /\left(z+z_{0}\right)
$$

Then we may express as

$$
\begin{array}{ll}
\varepsilon_{M}=\frac{c^{3} V^{3}{ }_{g, 0, M}}{\kappa} /\left(z_{M}+z_{0 M}\right) & \text { for the model flow, } \\
\varepsilon_{N}=\frac{c^{3} V^{3}{ }_{g, 0, N}}{\kappa} /\left(z_{N}+z_{0 N}\right) & \text { for the natural flow, }
\end{array}
$$

where suffixes $M$ and $N$ mean being related to model and prototype, respectively, but $\varepsilon_{M}$ means the rate of energy dissipation of the model flow per mass and time reduced according to both the reduced scale of the height and that of the wind velocity. From (3.12) and (3.13)

$$
\frac{\varepsilon_{M}}{\varepsilon_{N}}=\frac{V^{3}{ }_{g, 0, M}}{V^{3}{ }_{g, 0, N}} \cdot \frac{z_{N}+z_{0 N}}{z_{M}+z_{0 M}},
$$

then

$$
\frac{V_{g, 0, M}}{V_{g, 0, N}}=\left(\frac{\varepsilon_{M}}{\varepsilon_{N}}\right)^{\frac{1}{3}}\left(\frac{z_{M}+z_{0 M}}{z_{N}+z_{0 N}}\right)^{\frac{1}{3}},
$$

may be obtained. If

$$
\frac{z_{M}}{z_{N}}=\frac{z_{0 M}}{z_{0 N}}
$$

from (3.15)

$$
\frac{V_{g, 0, M}}{V_{g, 0, N}}=\left(\frac{\varepsilon_{M}}{\varepsilon_{N}}\right)^{\frac{1}{3}}\left(\frac{z_{0 M}}{z_{0 N}}\right)^{\frac{1}{8}},
$$

may be obtained, furthermore, since the relation

$$
\frac{V_{g, 0, M}}{V_{g, 0, N}}=\frac{U_{\infty M}}{U_{\infty N}},
$$

may hold, then from (3.16) 


$$
\frac{U_{\infty M}}{U_{\infty N}}=\left(\frac{\varepsilon_{M}}{\varepsilon_{N}}\right)^{\frac{1}{3}}\left(\frac{z_{0 M}}{z_{0 N}}\right)^{\frac{1}{3}},
$$

can be obtained. This relation corresponds to (5.5) in Part I.

But it is to be noticed that both $z_{0 M}$ and $z_{0 N}$ are to be determined from observations and the ratio $z_{0 M} / z_{0 N}$ is not necessarily equal to the reduced scale of the model rough surface. As the height dependency of $\varepsilon$ values similar to that shown in Fig. 1 of Part I may be considered with respect to model winds in the wind tunnel, the ratio of $\varepsilon$ values at each corresponding height, $\varepsilon_{M} / \varepsilon_{N}$, may be considered to have a constant value independent of height for given wind velocities, in spite of dependence of $\varepsilon_{M}$ and $\varepsilon_{N}$ on both height and wind velocity. Then, if both $z_{0 M}$ and $z_{0 N}$ do not vary with wind velocities, the wind profile of the model flow in the wind tunnel will become similar to that of the natural flow in the atmosphere for arbitrary wind velocity, but the similarity of turbulence structure of the two flows cannot be expected except for the case of $\varepsilon_{M}=\varepsilon_{N}$.

Furthermore, it will be described later that both the condition of dynamical similarity and that of geometrical similarity have been surely satisfied.

\section{Dynamical similarity and geometrical similarity}

The molecular kinetic viscosity coefficient have been generally used for the so-called Reynolds number usually used, but the eddy diffusion coefficient is used here in its place and it is called, for convenience, the eddy Reynolds number.

Let us now denote the eddy Reynolds number for the model experiment by $R_{M}$, then the eddy Reynolds number at a height of $z_{M}+d_{M}$ may be expressed by

$$
R_{M}=\frac{U_{M} \times\left(z_{M}+d_{M}\right)}{K_{z M}},
$$

where $U_{M}$ and $K_{z M}$ denote the mean wind velocity and the eddy diffusion coefficient in the vertical direction at a height of $z_{M}+d_{M}$, respectively. But, now $K_{z M}$ may be expressed as

$$
K_{z M}=\kappa v_{* M} \times\left(z_{M}+d_{M}\right),
$$

for the case where the vertical distribution of mean wind velocity has a logarithmic profile, where $v_{* M}$ means friction velocity for the model experiment. Hence, from eqs. (4.1) and (4.2)

$$
R_{M}=\frac{U_{M} \times\left(z_{M}+d_{M}\right)}{\kappa v_{* M} \times\left(z_{M}+d_{M}\right)}=\frac{1}{\kappa \gamma_{M}\left(z_{M}+d_{M}\right)},
$$

can be obtained. That is, it may be seen that the eddy Reynolds number is reciprocally proportional to the friction coefficient. On the other hand the eddy Reynolds number $R_{N}$ for the natural flow in the atmosphere may be similarly given as

$$
R_{N}=\frac{1}{\kappa \gamma_{N}\left(z_{N}+d_{N}\right)},
$$

but from the condition of (3.5)

$$
R_{M}=R_{N},
$$


may be obtained. That is, the condition equalizing each corresponding friction coefficient of both cases means in itself equalizing each corresponding eddy Reynolds number of both. Therefore, it may be found that the condition of dynamical similarity has been satisfied in this case. Furthermore, let us examine into the condition of geometrical similarity.

The distribution of mean wind velocity with height may be given, as previously described, in the form of

$$
U_{M}\left(z_{M}+d_{M}\right)=\frac{v_{* M}}{\kappa} \ln \frac{z_{M}+d_{M}}{z_{0 M}},
$$

for the model flow. Similarly,

$$
U_{N}\left(z_{N}+d_{N}\right)=\frac{v_{* N}}{\kappa} \ln \frac{z_{N}+d_{N}}{z_{0 N}},
$$

for the natural flow.

Let us now suppose that corresponding mean wind velocities at a height $\alpha$ times as large as the reference height are expressed by $U_{M a}$ and $U_{N a}$ for model and prototype, respectively. Then,

$$
\frac{U_{M \alpha}}{U_{M}}=\ln \frac{\alpha\left(z_{M}+d_{M}\right)}{z_{0 M}} / \ln \frac{z_{M}+d_{M}}{z_{0 M}},
$$

can be obtained for the model flow and for the natural flow, similarly,

$$
\frac{U_{N a}}{U_{N}}=\ln \frac{\alpha\left(z_{N}+d_{N}\right)}{z_{0 N}} / \ln \frac{z_{N}+d_{N}}{z_{0 N}} .
$$

But from eq. (3.7), since

$$
\frac{z_{N}+d_{N}}{z_{0 N}}=\frac{z_{M}+d_{M}}{z_{0 M}}
$$

then eq. (4.9) can be rewritten as

$$
\frac{U_{N \alpha}}{U_{N}}=\ln \frac{\alpha\left(z_{M}+d_{M}\right)}{z_{0 M}} / \ln \frac{z_{M}+d_{M}}{z_{0 M}} .
$$

Thus, from eq. (4.8) and eq. (4.10)

$$
\frac{U_{M a}}{U_{M}^{-}}=\frac{U_{N a}}{U_{N}},
$$

can be obtained. That is, each ratio of mean wind velocity at a height $\alpha$ times as large as the reference height to that at the reference height of both cases is equal. Namely, the condition of geometrical similarity has been also satisfied.

\section{Similarity between the wind profile above the model rough surface of the flat-plate and that above the urban district in the case of a typhoon}

As an example of natural local winds which should be compared with the model experiment, we use here the wind profile above the urban district in the case of a typhoon (these data have been obtained by the observation at the observation tower with the height of about $65 \mathrm{~m}$ of the Japan Meteorological 


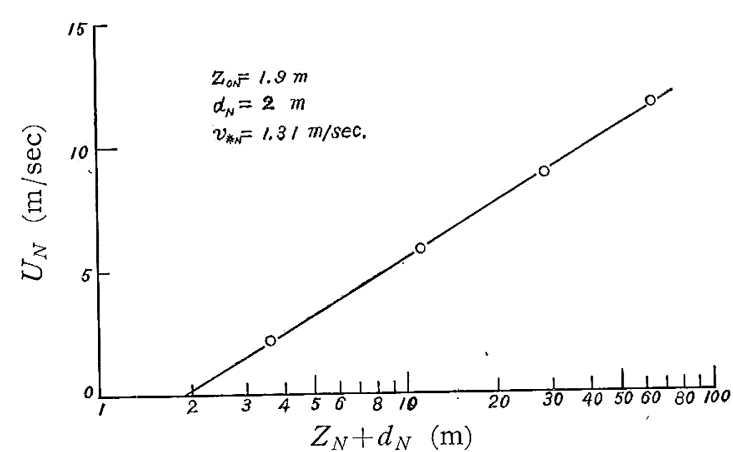

Fig. 6. Wind profile above the urban district in a typhoon. (weak wind)

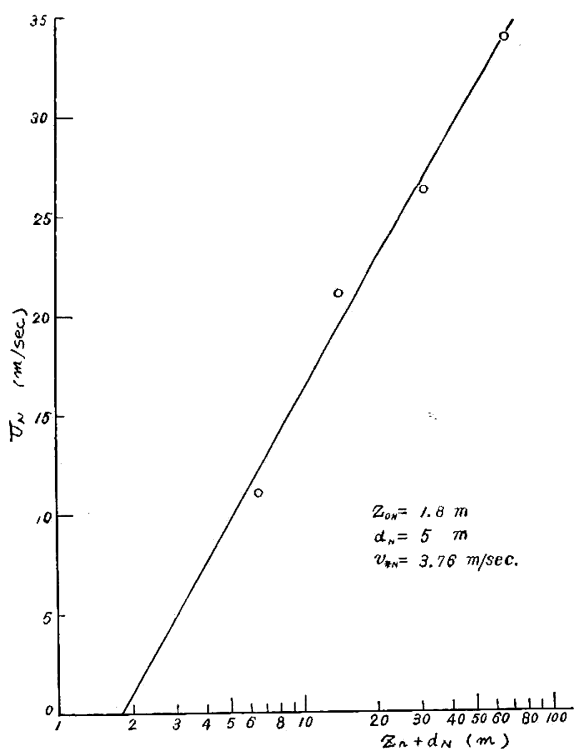

Fig. 7. Wind profile above the urban district in a typhoon. (strong wind)

Agency).* Figs. 6 and 7 show the results both in the case of a relatively weak wind and of a relatively strong wind, respectively. From these figures it will be found that if the zero plane displacement $d_{N}$ is taken into account these results may be well expressed by the logarithmic profile. Furthermore, from these figures the roughness parameter $z_{0 N}$ and the friction velocity $v_{* N}$ may be obtained as follows :

for the case of a relatively weak wind,

$$
\begin{aligned}
z_{0 N} & =1.9 \mathrm{~m} \\
d_{N} & =2 \mathrm{~m} \\
v_{* N} & =1.31 \mathrm{~m} / \mathrm{sec},
\end{aligned}
$$

and for the case of a relatively strong wind,

$$
\begin{aligned}
z_{0 N} & =1.8 \mathrm{~m} \\
d_{N} & =5 \mathrm{~m} \\
v_{* N} & =3.76 \mathrm{~m} / \mathrm{sec} .
\end{aligned}
$$

On the other hand, the result obtained for the model experiment in the wind tunnel is as follows: at a distance of about $150 \mathrm{~cm}$ downwind from the leading edge of the flat-plate, for the case of $50 \mathrm{~cm} / \mathrm{sec}$ of wind velocity in the wind tunnel,

$$
\begin{aligned}
z_{0 M} & =0.22 \mathrm{~cm} \\
d_{M} & =3.6 \mathrm{~cm} \\
v_{* M} & =4.95 \mathrm{~cm} / \mathrm{sec},
\end{aligned}
$$

* The author could quote these data through the kindness of Dr. Y. Takahashi. 
(in this case the thickness of wood wool is about $3.5 \mathrm{~cm}$ ). Then comparing this result obtained by the model experiment with the above two results, for the case of a relatively weak wind,

$\frac{z_{0 N}}{z_{0 M}}=863$ (magnification factor of height). This means that a height of $6.95 \mathrm{~cm}$ in the model flow corresponds to a height of $60 \mathrm{~m}$ in the natural flow, where it is to be noticed that height means height containing zero plane displacement.

$\frac{v_{* N}}{v_{* M}}=26.5$ (magnification factor of mean wind velocity).

On the other hand, for the case of a relatively strong wind,

$\frac{z_{0 N}}{z_{0 M}}=818$ (magnification factor of height). This means that a height of $7.34 \mathrm{~cm}$ in the model flow corresponds to a height of $60 \mathrm{~m}$ in the natural flow.

$\frac{v_{* N}}{v_{* M}}=76$ (magnification factor of mean wind velocity).

When the above-mentioned magnification factors are chosen, each wind profile to a height of $60 \mathrm{~m}$ of the prototype for two wind velocities coincides with only one wind profile obtained by the model experiment in the wind tunnel. So that it will be seen that the wind profile near the adiabatic surface layer can be reproduced by the model experiment in arbitrary mean wind velocity, regardless of wind velocity.

\section{Similarity between the wind profile near the ground and that above the model rough surface of the flat-plate in the wind tunnel in the case where the effect of the thermal stratification has been taken into account}

We have thus far described the similarity in the case where the vertical distribution of mean wind velocity could be expressed by the logarithmic profile, that is, in the case of the neutral state. Furthermore, let us again here discuss the similarity in the case where the effect of the thermal stability of the air layer has been considered, from another point of view.

A. S. Monin and A. M. OBukhov (1954), previously, have considered $\frac{g}{T_{0}}, v_{*}$ and $\frac{q}{c_{p_{p}} \rho}$ (where $g$ denotes acceleration of gravity, $T_{0}$ mean absolute temperature of the air layer, $q$ heat content, $c_{p}$ specific heat of the air at a constant pressure, $\rho$ air density, $v_{*}$ friction velocity) as characteristic quantities of turbulence near the ground, and using these parameters they denoted the scale of length $L_{s}$ (called stability length) and the scale of temperature $T_{*}$ as follows:

$$
\begin{aligned}
L_{s} & =\frac{v_{*}{ }^{3}}{\kappa \frac{g}{T_{0}}} \frac{q}{c_{p} \rho} \\
T_{*} & =-\frac{1}{\kappa v_{*}} \frac{q}{c_{p} \rho} .
\end{aligned}
$$

Thus,

$$
L_{s}=\frac{v_{*}^{2}}{\kappa^{2} g \frac{T_{*}}{T_{0}}},
$$


can be obtained by inserting eq. (6.2) into eq. (6.1). On the other hand, according to A.S. Monin and A.M. OBukhov (1954), in the case of $\left|\frac{z}{L_{s}}\right|<1$, the wind profile near the ground may be expressed in the form of

$$
U(z)=\frac{v_{*}}{\kappa}\left(\ln \frac{z}{z_{0}}+\beta \frac{z-z_{0}}{L_{s}}\right) .
$$

Now, if $z \gg z_{0}, \beta \frac{z-z_{0}}{L_{s}}$ may be replaced by $\beta \frac{z}{L_{s}}$. Then $U(z)$ can be reduced to

$$
U(z)=\frac{v_{*}}{\kappa}\left(\ln \frac{z}{z_{0}}+\beta \frac{z}{L_{s}}\right),
$$

where $\beta$ is a universal constant to be obtained from the experiment. Therefore, eq. (6.4) can be written for the model flow in the form of

$$
U_{M}\left(z_{M}\right)=\frac{v_{* M}}{\kappa}\left(\ln \frac{z_{M}}{z_{0 M}}+\beta \frac{z_{M}}{L_{s M}}\right)
$$

and on the other hand for the natural flow, similarly,

$$
U_{N}\left(z_{N}\right)=\frac{v_{* N}}{\kappa}\left(\ln \frac{z_{N}}{z_{0 N}}+\beta \frac{z_{N}}{L_{s N}}\right) .
$$

Hence, from our previous description, in order that the wind profile of the model experiment may become similar to that of the natural wind,

$$
\begin{aligned}
& \frac{z_{N}}{z_{0 N}}=\frac{z_{M}}{z_{0 M}}, \\
& \frac{z_{N}}{L_{s N}}=\frac{z_{M}}{L_{s M}},
\end{aligned}
$$

need to be simultaneously satisfied. From this

$$
\frac{L_{s N}}{L_{s M}}=\frac{z_{0 N}}{z_{0 M}},
$$

can be obtained, that is, it may be seen that the ratio between the stability lengths of both cases should be equal to that between their roughness parameters. Furthermore, eq. (6.9) may be transformed into

$$
\frac{v_{*}{ }^{2}{ }^{2}}{\kappa^{2} g_{N} \frac{T_{* N}}{T_{0 N}}} / \frac{v_{*}{ }^{2}{ }^{M}}{\kappa^{2} g_{M} \frac{T_{* M}}{T_{0 M}}}=\frac{z_{0 N}}{z_{0 M}} .
$$

Now, since it may be considered that $g_{N}$ is nearly equal to $g_{M}$, then

$$
\frac{v_{* N}}{v_{* M}}=\left(\frac{z_{0 N}}{z_{0 M}}\right)^{\frac{1}{2}}\left(\frac{T_{* M}}{T_{0 M}} / \frac{T_{* N}}{T_{0 N}}\right)^{\frac{1}{2}}
$$

can be obtained. But, since

then

$$
\frac{v_{* N}}{v_{* M}}=\frac{U_{N}\left(z_{N}\right)}{U_{M}\left(z_{M}\right)},
$$

$$
\frac{U_{N}\left(z_{N}\right)}{U_{M}\left(z_{M}\right)}=\left(\frac{z_{0 N}}{z_{0 M}}\right)^{\frac{1}{2}}\left(\frac{T_{* M}}{T_{0 M}} / \frac{T_{* N}}{T_{0 N}}\right)^{\frac{1}{2}}
$$


can be obtained, and the above relation corresponds to eq. (6.12) described in Part I. Because, since eq. (6.12) described in Part I can be rewritten as

$$
\frac{U_{\infty N}}{U_{\infty M}}=\left(\frac{L_{N}}{L_{M}}\right)^{\frac{1}{2}}\left(\frac{\theta_{M}}{\Delta \theta_{M}} / \frac{\theta_{N}}{\Delta \theta_{N}}\right)^{\frac{1}{2}}
$$

then, in this equation, by replacing, formally, $U_{\infty_{N}} / U_{\infty_{M}}$ with $U_{N}\left(z_{N}\right) / U_{M}\left(z_{M}\right), L_{N^{N}} / L_{M}$ with $z_{0 N} / z_{0 M}$ and $\frac{\theta_{M}}{\Delta \theta_{M}} / \frac{\theta_{N}}{\Delta \theta_{N}}$ with $\frac{T_{* M}}{T_{0 M}} / \frac{T_{* N}}{T_{0 N}}$, eq. (6.11) may be obtained immediately.

\section{Summary}

The main results described in the present paper may be summarized as follows :

(i) Condition of similarity between the wind profile near the ground and that above the model rough surface horizontally set in a wind tunnel under the neutral state is that each friction coefficient $\gamma$ for corresponding heights containing $d$ of both cases should be identical with each other, and this means that

$$
\frac{z_{M}+d_{M}}{z_{N}+d_{N}}=\frac{z_{0 M}}{z_{0 N}} \text { and } \frac{U_{M}\left(z_{M}+d_{M}\right)}{U_{N}\left(z_{N}+d_{N}\right)}=\frac{v_{* M}}{v_{* N}}
$$

should be simultaneously satisfied. Therefore, this means also that so long as the reduced scale of height of the two cases (model and natural flow) is equal to the ratio of roughness parameters $z_{0 M} / z_{0 N}$, the similarity of the wind profile of both cases should be satisfied regardless of the wind velocity. Then, when it is desired to make the model experiment for the adiabatic surface layer, the wind velocity can be adequately and arbitrary chosen but in this case the similarity of turbulence structure of both cases cannot be expected except for the case of $\varepsilon_{M}=\varepsilon_{N}$. Furthermore, these conditions have satisfied both dynamical similarity and geometrical similarity. But the latter does not mean the similar geometrical construction of the rough surface.

(ii) Condition of similarity between the wind profile near the ground and that above the model rough surface of the flat-plate set in a wind tunnel in the case where the effect of the thermal stratification has been considered, is that the ratio between the roughness parameters of both cases should be equal to the ratio of stability lengths of both cases, that is,

$$
\frac{L_{s N}}{L_{s M}}=\frac{z_{0 N}}{z_{0 M}} .
$$

Furthermore, this relation may be transformed into

$$
\frac{U_{N}\left(z_{N}\right)}{U_{M}\left(z_{M}\right)}=\left(\frac{z_{0 N}}{z_{0 M}}\right)^{\frac{1}{2}}\left(\frac{T_{* M}}{T_{0 M}} / \frac{T_{* N}}{T_{0 N}}\right)^{\frac{1}{2}}
$$

and this relation corresponds to eq. (6.12) previously described in Part I.

Acknowledgement-The author wishes to express his sincere thanks to Dr. Y. Takahashi, Chief of the Laboratory of Physical Meteorology, for his suggestive advice on the present work. 


\section{References}

Takahashi, Y., Soma, K. and Nemoto, S., 1951: Experiment reproducing atmospheric turbulent flow by a model experiment in a wind tunnel. (read in the lecture meeting of the Meteorological Society of Japan in 1951)

Neмото, S., 1961: Similarity between natural wind in the atmosphere and model wind in a wind tunnel, Part I. Pap. Met. Geophys. 12, 30-52.

Monin, A.S. and Oвекноv, A. M., 1954: Fundamental law of the turbulent transport in the atmospheric surface layer. Akad. Nauk. S.S.S.R., Trud. Geofiz Inst., 24, (151), 163.

Lettau, H., 1961: Dissipation of energy by turbulence. J. Met. 18, 125-126.

LeTtAu, H., 1959: Wind profile, surface stress and geostrophic drag coefficients in the atmospheric surface layer. SAdvances in Geophysics. vol. 6. (Proceeding of symposium on atmospheric diffusion and air pollution held at Oxford, August, 1958). Academic Press. New York, London, 241-257.

\section{局地風の模型実験について}

\section{一第 2 報 地面附近の wind profile と風洞気流中の \\ 模型粗面上の wind profile の相似 -}

$$
\text { 根本茂 }
$$

地面附近の wind profile と風洞気流中の模型粗面上の wind profile の相似飞ついては，既飞，高橋， 相馬, 根本 (1951) が取报つているが, これを別な観点から取扱つた。

即も，中立状態に扣いて，地面附近の wind profile と模型粗面上の wind profile が相似であるため飞 は，模型の流れと自然の流れの対応する高さ（dを含えだ高さ）飞特ける糜擦係数 $\gamma$ が互飞等しければよ い。これは，

$$
\frac{z_{M}+d_{M}}{z_{N}+d_{N}^{i}}=\frac{z_{0 M}}{z_{0 N}} \text { 洛よび } \frac{U_{M}\left(z_{M}+d_{M}\right)}{U_{N}\left(z_{N}+d_{N}\right)}=\frac{v_{* M}}{v_{* N}}
$$

が同時に成立することを意味し，模型と自然の場合の高さの縮率を，その時の roughness parameter の 比等しくとりさえすれば, roughness parameterが風速によつて変らない限り，任意の風速で，両者の wind profile が相似になり，その時の風速の繀率は friction velocity の比に等しい（但し，この場合， 粗面は必ずしも幾何学的飞相似であるとは限らない)。この場合画者の対応する eddy Reynolds number は勿論いつでも一致しているが， $\varepsilon_{M}=\varepsilon_{N}$ の場合以外には雨者の乱流瑇造は相似にならない。

一方, 温度成層のある場合飞は，両者の roughness parameter の比と stability length の比を等し くしてやればよいという結果が得られた。これはまた

$$
\frac{U_{N}\left(z_{N}\right)}{U_{M}\left(z_{M}\right)}=\left(\frac{z_{0 N}}{z_{0 M}}\right)^{\frac{1}{2}}\left(\frac{T_{* M}}{T_{0 M}} / \frac{T_{* N}}{T_{0 N}}\right)^{\frac{1}{2}}
$$

なること意沬している。

尚, 中立状態の場合の一つの具体例として，台風時飞特ける市街地上の wind profile と模型粗面上の

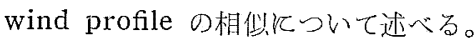

